\author{
UNIVERSIDADE FEDERAL DE SANTA CATARINA \\ CENTRO DE CIÊNCIAS DA EDUCAÇÃO \\ DEPARTAMENTO DE CIÊNCIA DA INFORMAÇÃO \\ PROGRAMA DE PÓS-GRADUAÇÃO EM CIÊNCIA DA INFORMAÇÃO \\ ENCONTROS BIBLI: revista de Biblioteconomia e Ciência da Informação
}

\title{
A PUBLICAÇÃo DE PERIÓdICOS CIENTÍFICOS DIGITAIS
}

Os periódicos científicos aumentam sua importância na medida em que Ciência e Tecnologia são entendidas como essenciais para o desenvolvimento sustentável dos países e bem estar da população. Como responsáveis pela certificação e divulgação dos resultados das pesquisas em todas as áreas, os periódicos são os canais de comunicação prioritários da ciência.

Em função da relevância crescente da publicação científica em todas as áreas do conhecimento, os periódicos são pressionados, cada vez mais, a elevar seus padrões de qualidade, com o objetivo de atrair mais e melhores artigos, o que implica em maior número de leitores e citações. As instituições de fomento e avaliação da ciência consideram a publicação como elemento final do ciclo da pesquisa e indicador quantitativo e qualitativo para a construção de confiabilidade e prestígio para os indivíduos, grupos e instituições que formam a rede.

A Ciência da Informação é uma área que tem o estudo da Comunicação Científica como uma de suas principais vertentes, e esta condição exige que tenhamos excelentes e inovadores periódicos. A Encontros Bibli: revista de biblioteconomia e ciência da informação é pioneira, sendo a primeira revista exclusivamente digital da Ciência da Informação no Brasil.

Em 1996, no dia 09 de maio, a revista Encontros Bibli, por iniciativa do então Departamento de Biblioteconomia e Documentação, atual Departamento de Ciência da Informação da Universidade Federal de Santa Catarina (UFSC), ingressava na Web, a

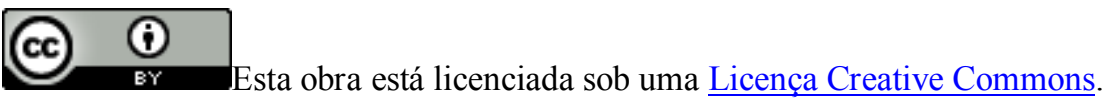

DOI $10.5007 / 1518-2924.2011 \mathrm{v} 16 \mathrm{n} 31 \mathrm{pi}$ 
partir de seu primeiro número, utilizando a ferramenta HTML e, mais tarde, agregando outros recursos de edição, como a edição final dos textos em PDF. Desde então, a revista tem se mantido neste ambiente, com periodicidade semestral e publicação de edições especiais.

Em 2003, a Encontros Bibli foi incluída na Rede de Revistas Cientificas da América Latina, Caribe, Espanha e Portugal (REDALYC) e no Sistema Regional de Información para las Revistas Científicas de América Latina, el Caribe, España y Portugal (LATINDEX), passando a ser espelhada por esses diretórios e tendo, adicionalmente, mais fontes de acesso a seus conteúdos.

$\mathrm{Na}$ avaliação de periódicos nacionais, obteve reconhecimento pelo QUALIS/CAPES (http://qualis.capes.gov.br/webqualis/), sendo avaliada no nível NACIONAL “A”, em 2003, e na categoria B2, em 2009, na área de Ciências Sociais Aplicadas.

Em 2007, a equipe editorial da Encontros Bibli lidera a criação do Portal de Periódicos na UFSC e migra para a plataforma SEER. Em 2009, a gestão do Portal passa a ser de responsabilidade da Biblioteca Central da UFSC, porém é mantido um membro da equipe editorial da Encontros Bibli como integrante permanente no Conselho Editorial do Portal de Periódicos da UFSC.

Ao dar sequencia às atividades relacionadas ao Acesso Aberto e com o intuito de acompanhar a evolução tecnológica, editorial e de gestão de periódicos, a equipe editorial da revista cria a Incubadora de Periódicos da UFSC, com o objetivo de contribuir para a criação, migração e gestão de novos periódicos, como também contribuir para o desenvolvimento de pesquisas sobre publicação científica digital.

A partir do fascículo 30, publicado em outubro de 2010, a Encontros Bibli passa a contar com o identificador Digital Object Identifier (DOI) em seus artigos e torna o editorial uma prática do Portal de Periódicos, sendo incluído em todas as revistas da UFSC. Nos artigos dos fascículos anteriores a 2010, o número do DOI será incluído paulatinamente.

Os indicadores da revista até abril de 2011 apresentam: 1175 usuários cadastrados e 950 leitores. A média de acessos mensal é de 9.000 visitantes únicos. Destacamos o acesso dos últimos anos, que ultrapassou a marca de cem mil acessos únicos anuais, e salientamos a participação de colegas de diversos países. 
Para esta edição, expressamos nossos agradecimentos, em primeiro lugar, aos professores, alunos e pesquisadores que consideraram nossa revista uma fonte de referência para submeter seus trabalhos. É uma grande honra receber tantos artigos. Dos 26 trabalhos apresentados para esta edição, 19 se enquadravam nas normas da revista e foram avaliados por 35 professores e pesquisadores renomados nas áreas e que deram contribuições valiosas para todos os envolvidos. Dos trabalhos submetidos ao crivo dos pareceristas, 7 foram aprovados para compor esta edição: cinco artigos e dois ensaios. O primeiro artigo, "As redes sociais em linguagens documentais", apresenta a formação de redes sociais relacionadas ao tema da linguagem documental a partir dos currículos disponibilizados na Plataforma Lattes. O segundo, "Avaliação do espectro semântico de instrumentos para organização da informação", analisa o que é semântica, discutindo-a no âmbito da tecnologia da informação e propondo alternativas interpretativas. $\mathrm{O}$ terceiro, "A bibliometria na pesquisa científica da pós-graduação brasileira de 1987 a 2007”, apresenta a inserção dos estudos bibliométricos na pesquisa científica da pósgraduação no Brasil, a partir da análise de teses e dissertações que abordaram aspectos de estudos bibliométricos. A seguir, o trabalho "Aspectos do consumo e da produção da informação no campo científico da administração" mostra o conjunto de periódicos citados nas teses de doutorado em Administração da Universidade Federal do Rio Grande do Sul concluídas entre 1997 e 2007 e os diversos periódicos em que os autores destas teses publicaram seus artigos técnicos e científicos. O quinto artigo, "O prêmio jovem cientista e o comportamento informacional do pesquisador", buscou investigar o comportamento informacional do jovem pesquisador brasileiro.

Também constam nessa edição dois ensaios: o primeiro, com o titulo "A dimensão categórica do documento na ciência da informação", apresenta um estudo históricoconceitual do documento na ciência da informação, com vistas a remontar aspectos teóricos, com base nas disciplinas de história, diplomática e documentação. O segundo ensaio, intitulado "Ciência da informação, biblioteconomia, arquivologia e museologia", traz uma discussão sobre as relações entre a Ciência da Informação e os campos da Biblioteconomia, Arquivologia e Museologia, a partir de dois critérios: as questões de legitimação institucional e as relações teórico-científicas.

E, finalmente, compõe esta edição um dossiê de título "Estudos e ações em informação e educação - 2010", que apresenta o relatório final do III Seminário Estudos e Ações 
em Informação e Educação, realizado em Florianópolis, nos dias 6, 7 e 13 de dezembro de 2010 .

Em maio de 2011, data em que se comemora os 15 anos da Encontros Bibli, temos um editorial escrito por muitas mãos, o que representa o cenário contemporâneo da comunicação científica, marcado pela colaboração entre cientistas e pela busca permanente do aprimoramento. E é assim que a Encontros Bibli pretende trilhar os próximos 15 anos, a serviço dos autores, avaliadores e leitores da Ciência da Informação e das áreas correlatas. Sempre contando com mais artigos, mais indexações, mais interlocutores internacionais, consolidando-se como um veículo de excelência na construção da Ciência da Informação e áreas relacionadas.

\author{
Rosângela Schwarz Rodrigues \\ Ursula Blattmann \\ Araci Isaltina Andrade Hillesheim \\ Gleisy Regina Bories Fachin
}

